\title{
Publisher Correction to: Severe adverse events due to dihydropyrimidine dehydrogenase deficiency in a Japanese patient with colon cancer taking capecitabine: a case report
}

Mai Tsutsui $^{1}$ - Seiichiro Yamamoto ${ }^{1}$. Yusuke Yoshikawa ${ }^{1} \cdot$ Ryo Nakanishi $^{1} \cdot$ Kiminori Takano $^{1} \cdot$ Koji Osumi $^{1}$. Tomotaka Akatsu ${ }^{1} \cdot$ Kimiyasu Yoneyama $^{1} \cdot$ Motohito Nakagawa $^{1} \cdot$ Toshio Kanai $^{1}$

Published online: 7 July 2018

(c) The Japan Society of Clinical Oncology 2018

\section{Publisher Correction to: International Cancer Conference Journal https://doi.org/10.1007/s13691-018-0334-1}

The publisher regrets that in the original version of this article, unfortunately the word "phosphate" in Fig. 1 has been misspelt as "phosohate".

The original article has been corrected.

The original article can be found online at https://doi.org/10.1007/ s13691-018-0334-1.

Seiichiro Yamamoto

miyamamo@jcom.home.ne.jp

1 Department of Surgery, Hiratsuka City Hospital, 1-19-1, Minamihara, Hiratsuka, Kanagawa 254-0065, Japan 